\title{
Maximum Torque Control of an IPMSM Drive Using an Adaptive Learning Fuzzy-Neural Network
}

\author{
Jae-Sub Ko*, Jung-Sik Choi ${ }^{* *}$, and Dong-Hwa Chung ${ }^{\dagger}$ \\ $\dagger^{*}$ Dept. of Electrical Control Eng., Sunchon National University, Sunchon, Korea \\ ${ }^{* *}$ Korea Electronics Technology Institute, Gwangju, Korea
}

\begin{abstract}
The interior permanent magnet synchronous motor (IPMSM) has been widely used in electric vehicle applications due to its excellent power to weigh ratio. This paper proposes the maximum torque control of an IPMSM drive using an adaptive learning (AL) fuzzy neural network (FNN) and an artificial neural network (ANN). This control method is applicable over the entire speed range while taking into consideration the limits of the inverter's rated current and voltage. This maximum torque control is an executed control through an optimal d-axis current that is calculated according to the operating conditions.

This paper proposes a novel technique for the high performance speed control of an IPMSM using AL-FNN and ANN. The AL-FNN is a control algorithm that is a combination of adaptive control and a FNN. This control algorithm has a powerful numerical processing capability and a high adaptability. In addition, this paper proposes the speed control of an IPMSM using an AL-FNN, the estimation of speed using an ANN and a maximum torque control using the optimal d-axis current according to the operating conditions. The proposed control algorithm is applied to an IPMSM drive system. This paper demonstrates the validity of the proposed algorithms through result analysis based on experiments under various operating conditions.
\end{abstract}

Key words: Artificial neural network, Fuzzy neural network, IPMSM drive, Maximum torque control, Speed estimation

\section{INTRODUCTION}

Recently, IPMSM drives has been widely used in many applications such as electric vehicles, air conditioning compressors and machine tool spindle drives due to their many advantages such as high efficiency, high power density, high torque-to-inertia ration, wide speed operation range and maintenance free operation [1],[2]. They also have the characteristic of high mechanical strength. However, the operation from the constant torque region to the constant power region is difficult because it has salient pole and an inefficient air gap [3]. They can not obtain maximum torque and have a very low speed range in the constant power region within the fixed flux level. Therefore, the field weakening control, which increases the speed and the generated maximum torque in the constant power region, has been the subject of a lot of research [4]-[9]. In these papers, magnetic flux information is needed to

Manuscript received May 24, 2010; revised Jan 17, 2012

Recommended for publication by Associate Editor Jang-Mok Kim.

†Corresponding Author: hwa777@sunchon.ac.kr

Tel: +82-61-750-3543, Fax: +82-61-752-1103, Sunchon Nat'l Univ.

*Dept. of Electrical Control Eng,. Sunchon National University, Korea

${ }^{* *}$ Korea Electronics Technology Institute., Korea change the control mode from the constant torque region to the constant power region.

A voltage compensator can reduce the performance of an IPMSM when the magnetic flux weakens as a result of a voltage error due to temperature increases and dc link voltage changes [10]. Therefore, a novel approach that can be operated efficiently in the high speed area and can smoothly change control modes is needed.

Artificially intelligent controls such as fuzzy, neural network, genetic algorithms and adaptive control are recognized as important technique which can improve the performance of power electronics systems. In addition, novel artificial intelligent controls through a combination of these methods have been used in various application which demanded robustness and adaptability [11]-[15]. This paper proposes a maximum torque control that will work in all of the operation regions of an IPMSM drive by AL-FNN and ANN. The AL-FNN controller controls the speed and outputs the command q-axis current. The maximum torque control is the calculated d-axis current according to the operation conditions, and this current is used in each control mode. Furthermore, the ANN controller is used for speed estimation.

To prove validity of the proposed algorithm, this paper 


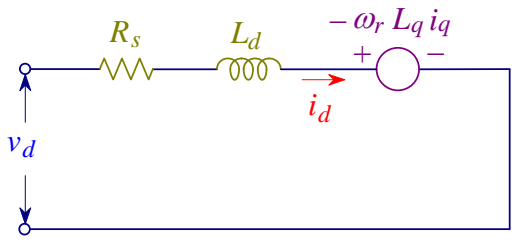

(a) $d$ axis

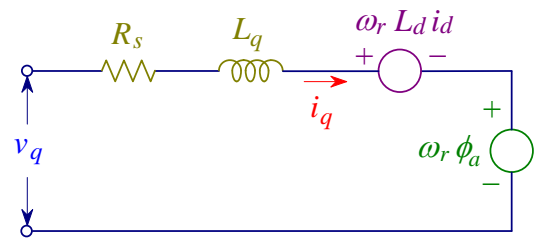

(b) $q$ axis

Fig. 1. Equivalent circuit of IPMSM.

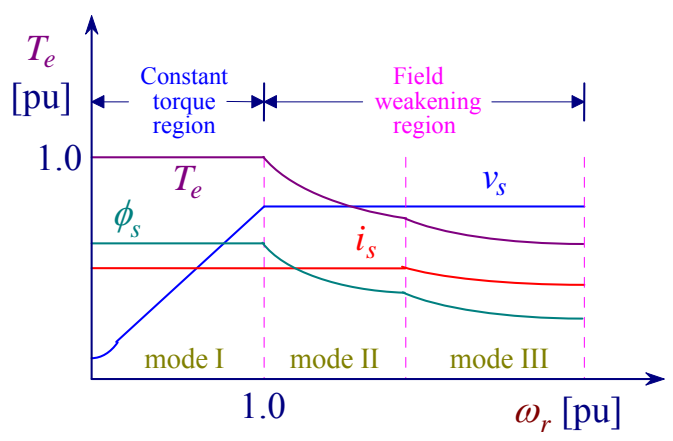

Fig. 2. Torque-speed curve in forward motoring.

proposes an analysis of the response characteristics under various operation conditions such as command speed and load torque changes.

\section{SYSTEM CONFIGURATION AND OPERATION STATE}

\section{A. Modeling}

Fig. 1 shows an equivalent circuit of the d-q frame of an IPMSM.

The differential equations for an analysis of the operation characteristics of an IPMSM are expressed as follows:

$$
\begin{gathered}
p i_{d}=\left(v_{d}-R i_{d}+\omega_{r} L_{q} i_{q}\right) / L_{d} \\
p i_{q}=\left(v_{q}-R i_{q}-\omega_{r} L_{d} i_{d}-\omega_{r} \phi_{a}\right) / L_{q} \mathrm{n} \\
p \omega_{r}=\left(T_{e}-T_{L}-B \omega_{r}\right) / J
\end{gathered}
$$

The electromagnetic torque is expressed as follows:

$$
T_{e}=\frac{3}{2} P\left[\phi_{a f} i_{q}+\left(L_{d}-L_{q}\right) i_{d} i_{q}\right]
$$

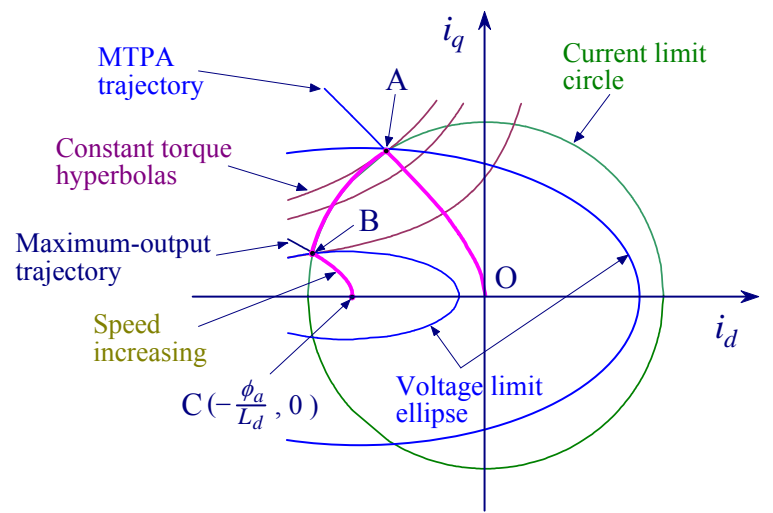

Fig. 3. Current locus in $i_{d}-i_{q}$ plane.

Fig. 2 shows the torque-speed curve in forward operation.

The operation regions of the forward motor classify the constant torque region (CTR) and the field weakening region (FWR). The CTR is mode I. Mode I is operated with PWM, the stator flux and current are constant, while the voltage changes. The FWR has two areas. Mode II is constant power region, the voltage and current are constant, while the torque and flux are reduced. Mode III is the voltage limit region, the voltage in this region is constant. The stator current, torque and magnet flux are reduced.

Fig. 3 shows the current trace in the $i_{d}-i_{q}$ plane about the limit conditions of the current and voltage.

Mode I : The current limit region by the constant maximum torque $\left(\omega_{r}<\omega_{1}\right)$

Mode $\mathrm{I}$ is a low speed region that generates the maximum torque which is operated under the optimal current angle and current limit. This accords the A point $i_{d}-i_{q}$ plane and the torque trace is a closed constant current circle. The voltage limit is defined as the maximum speed in mode I. This region is operated with the maximum torque per ampere (MTPA) control.

Mode II : The current and voltage limit region $\left(\omega_{1}<\omega_{r}<\omega_{2}\right)$

In mode II, the motor is operated from A point to B point following the constant current limit circle. The speed in this region is increased because the size of the constant voltage ellipse is decreased.

Mode III : Voltage limit region $\left(\omega_{2}<\omega_{r}\right)$

If the speed is increased then the current is decreased. In this case, to generate current, a constant voltage is not enough. The motor is operated under the optimum condition that is a closed torque trace to a constant voltage ellipse. In other words, the torque is maximized in each value about the speed over B point.

\section{B. Operating state}




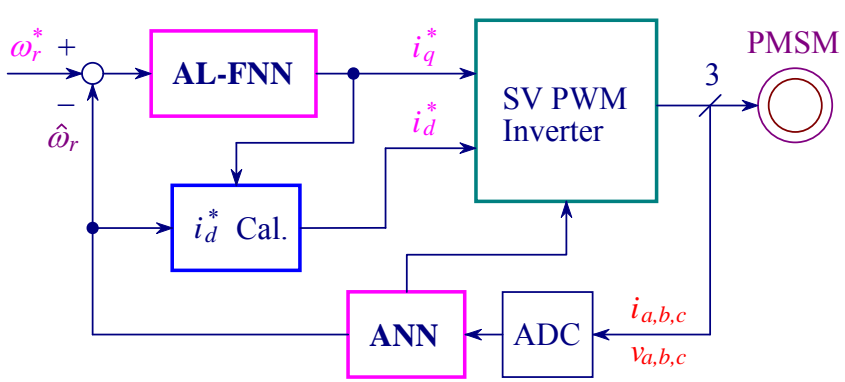

Fig. 4. Control block diagram of drive system in CTR.

\section{MAXIMUM TORQUE CONTROL}

\section{A. Drive in CTR}

The CTR is operated from O to A in Fig. 3. The speed is extended from zero to the rated speed. The IPMSM uses the reluctance torque because it has $L_{d}<L_{q}$ because of its salient pole structure. In the CTR region, the current vector is controlled for generating the MTPA.

The stator current and voltage are expressed as follows:

$$
\begin{gathered}
v_{d}^{2}+v_{q}^{2}=v_{s}^{2} \\
i_{d}^{2}+i_{q}^{2}=i_{s}^{2}
\end{gathered}
$$

The condition of the maximum torque control is expressed as follows:

$$
\frac{\partial T_{e}}{\partial i_{d}}=0
$$

$i_{d}$ is expressed as follows by (7).

$$
i_{d}=\frac{\phi_{a}}{2\left(L_{q}-L_{d}\right)}-\sqrt{\frac{\phi_{a}^{2}}{4\left(L_{d}-L_{q}\right)^{2}}+i_{q}^{2}}
$$

Fig. 4 is a system block diagram of an IPMSM drive

\section{B. Drive in FWR}

1) Voltage and current limit region $\left(\omega_{1}<\omega_{r}<\omega_{2}\right)$ : This region is operated according to the constant current circle from A to B in Fig. 3. A condition of the current and voltage is expressed as follows:

$$
V_{o}=\sqrt{v_{d o}^{2}+v_{q o}^{2}} \leq V_{o m}
$$

$$
I_{o}=\sqrt{i_{d o}^{2}+i_{q o}^{2}} \leq I_{o m}
$$

(1) and (2) are expressed as follows by (9).

$$
\begin{gathered}
v_{d o}=-\omega_{r} L_{q} i_{q} \\
v_{q o}=\omega_{r} L_{d} i_{d}+\omega_{r} \phi_{a} \\
V_{o m}=V_{a m}-R I_{a m}
\end{gathered}
$$

The relation of $i_{d}$ and $i_{q}$ in FWR region can be derived using (9) and (11)-(13).

$$
i_{d}=-\frac{\phi_{a}}{L_{d}}+\frac{1}{L_{d}} \sqrt{\frac{V_{o m}^{2}}{\omega_{r}^{2}}-\left(L_{q} i_{q}\right)^{2}}
$$

where $\left|i_{q}\right| \leq V_{0 m} /\left(\omega_{r} L_{q}\right)$, i.e, $\left|v_{d 0}\right| \leq V_{0 m}$.

If the motor is operated in a FWR exceeding the rated speed then $i_{d}^{*}$ is controlled by using (14) in the block diagram of Fig. 4.

2) Voltage limit region $\left(\omega_{2}<\omega_{r}\right)$ : This region is considered to be a term of two. Fig. 5 shows the operation mode of the motor. Fig. 5(a) satisfy the term of $\phi_{a}<L_{d} I_{o m}$. If the speed is above $\omega_{2}$ then the motor is operated form B to C. Fig. 5(b) shows the term of $\phi_{a}>L_{d} I_{o m}$ and the voltage limit trace exists outside the constant current circle. Operation in this region can not be achieved and so region of mode III does not existed.

If the operating mode is satisfied by a term of Fig. 5(a) than the trace of the constant maximum torque in each operating point is formed tangent to the direction of a $V_{o m} / \omega_{r}$ ellipse and satisfies the condition of the follwoing:

$$
\frac{\partial T_{e}}{\partial i_{d}}=0, \quad \frac{\partial\left(V_{o m} / \omega_{r}\right)}{\partial i_{d}}=0
$$

$i_{d}$ is expressed as follows:

$$
i_{d}=\frac{-\left(2 L_{d}-L_{q}\right) \phi_{a}+L_{q} \sqrt{\phi_{a}^{2}+4\left(L_{d}-L_{q}\right)^{2} i_{q}^{2}}}{2 L_{d}\left(L_{d}-L_{q}\right)}
$$

$i_{d}^{*}$ of mode III in the FWR region is controlled using (16) in the system block diagram of Fig. 4 [9]. 


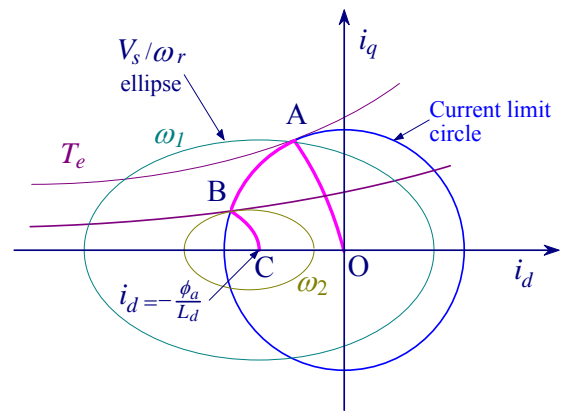

(a) $\phi_{a}<L_{d} I_{o m}$

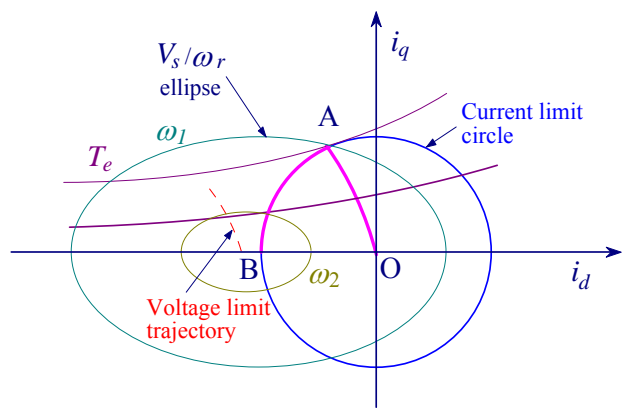

(b) $\phi_{a}>L_{d} I_{o m}$

Fig. 5. Operating mode of motor.

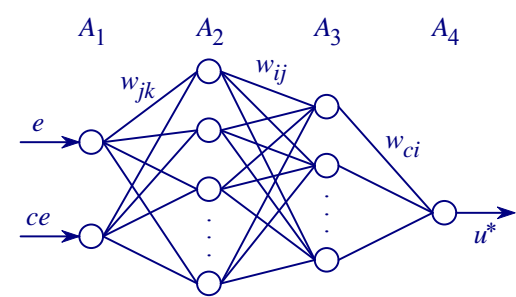

Fig. 6. The construction of FNN.

\section{DESIGN OF THE AL-FNN CONTROLLER}

\section{A. Design of the FNN Controller}

The FNN controller is compounded from fuzzy and neural network control. It has the robustness of fuzzy control and the adaptability of a neural network.

Fig. 6 shows the FNN controller, where the two input variables are the speed error $e$, and the change in the speed error ce respectively. The one output is control value is $u$.

1) Implementation of the Antecedent Parts of the FNN Controller: The neural networks between the layers $A_{1}$ and $A_{3}$ in Fig. 6 show the implementation of the antecedent parts of the fuzzy rule.

The error function is expressed as follows:

$$
E=\frac{1}{2} \sum_{i=0}^{r}\left(T_{i}-O_{i}\right)^{2}
$$

Where, $r$ is the number of clusters, $T_{i}$ is a function to determine whether a certain input data belongs to the desired cluster or not, and $O_{i}$ is the output of the neuron at layer $A_{3}$.

After defining the error function, to minimize the error, the weights $W_{j k}$ and $W_{i j}$ between the layers $A_{1}$ and $A_{3}$ are adjusted by the error backpropagation algorithm. Through the weight adjustment, the neural network can completely implement the antecedent parts of the clustered fuzzy rules.

$$
\begin{gathered}
\Delta W_{i j}=-\eta \frac{\partial E}{\partial W_{i j}}=-\eta \delta_{i} O_{j} \\
\Delta W_{j k}=-\eta \frac{\partial E}{\partial W_{j k}}=-\eta \delta_{j} X_{k}
\end{gathered}
$$

Where $\delta_{i}=\left(T_{i}-O_{i}\right) f^{\prime}\left(U_{i}\right)$

$$
\delta_{j}=f^{\prime}\left(U_{j}\right) \sum \delta_{i} W_{i j}
$$

$O_{i}$ is the output of the neuron at layer $A_{2}, \eta$ is the learning rate, $f^{\prime}(\cdot)$ is the derivative of the sigmoid function, and $U_{i}$ and $U_{j}$ are the total input to each neuron at the layers $A_{2}$ and $A_{3}$, respectively.

Finally, to avoid vibration during the process of learning and to improve the convergence speed, a new adjustment with a momentum term as follows will be assumed.

$$
\begin{aligned}
& W_{i j}(t+1)=W_{i j}(t)+\Delta W_{i j}+\alpha\left[W_{i j}(t)-W_{i j}(t-1)\right] \\
& W_{j k}(t+1)=W_{j k}(t)+\Delta W_{j k}+\alpha\left[W_{j k}(t)-W_{j k}(t-1)\right]
\end{aligned}
$$

where $\alpha(0<\alpha<1)$ is the momentum term.

\section{2) Implementation of the Consequent Parts of the FNN} Controller: In Fig. 6, the neural network between layers $A_{3}$ and $A_{4}$ shows the implementation of the consequent parts of the fuzzy rule. During the learning, the weight $W_{c i}$ will be adjusted to minimize the following error function.

$$
E^{*}=\frac{1}{2} \sum\left(U^{*}-U\right)^{2}
$$

where $U^{*}$ and $U$ represent the values of the desired and 


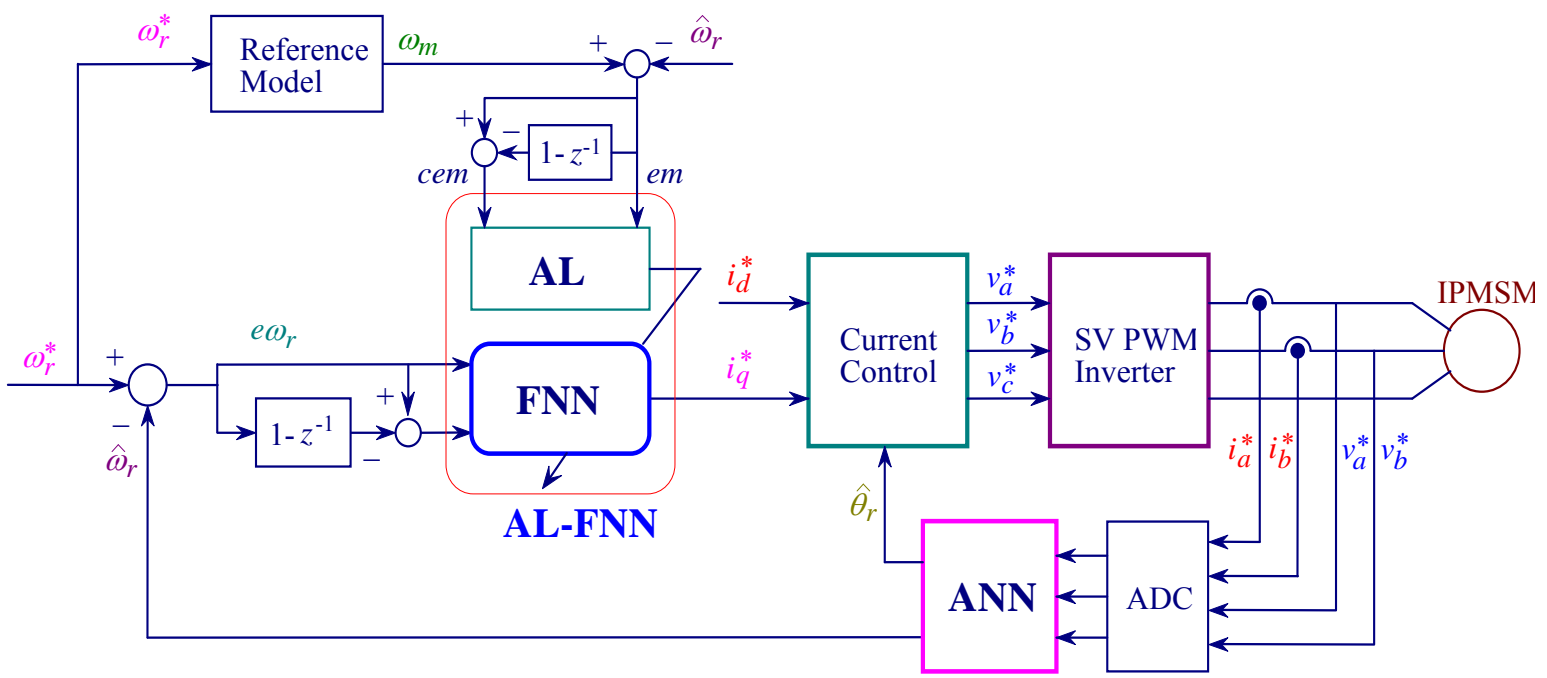

Fig. 7. Drive system with AL-FNN controller.

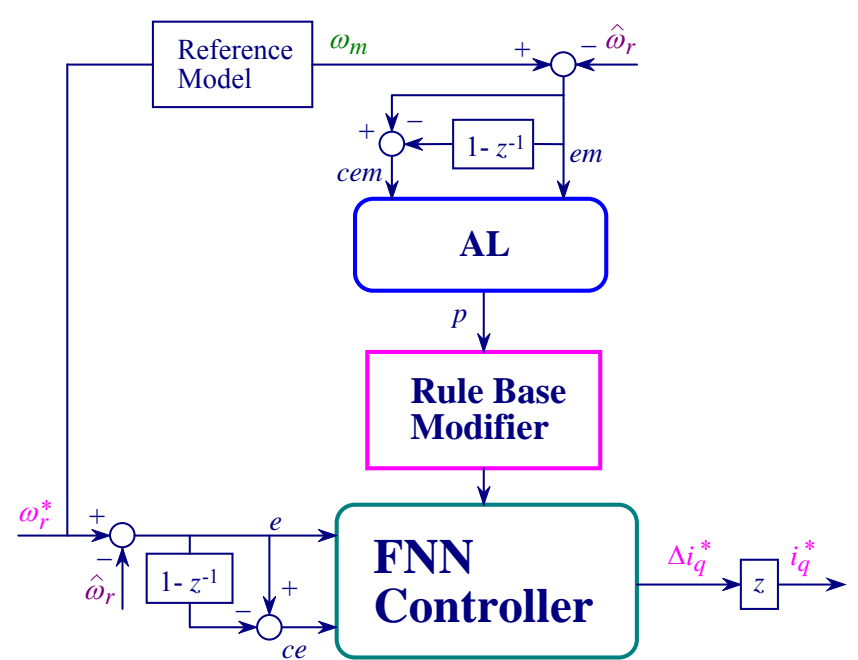

Fig. 8. AL-FNN Controller with adaptive learning mechanism.

actual outputs of the FNN controller.

Using the generalized delta rule, the variation $\Delta W_{c i}$ of the weight $W_{c i}$, which can minimize the error function (24) and refine the consequent parts of the fuzzy rules, can be determined as follows:

$$
\begin{gathered}
\Delta W_{c i}=-\eta \frac{\partial E^{*}}{\partial W_{c i}}=-\eta \delta_{c} O_{i} \\
W_{c i}(t+1)=W_{c i}(t)+\Delta W_{c i}+\alpha\left[W_{c i}(t)-W_{c i}(t-1)\right]
\end{gathered}
$$

where $\delta_{c}$ is the error signal at the output of the FNN controller.

\section{B. Design of the AL-FNN Controller}

Fig. 7 shows the AL-FNN controller for an IPMSM drive system.

Fig. 8 shows structure of the AL-FNN controller using adaptive control and a FNN.

The AL includes the fuzzy inverse model and the modifier of the rule base. The speed performance of a drive system is the decided error between the reference model speed and the estimation speed. The reference model is a 1st-order delay function.

$$
\begin{gathered}
\omega_{m}(k)=\omega_{r}^{*}(k-1) \\
e m(k T)=\omega_{m}(k T)-\hat{\omega}_{r}(k T) \\
\operatorname{cem}(k T)=e m(k T)-e m(k T-T)
\end{gathered}
$$

The rule base of the FNN is changed according to $p(k T)$. This change is realized through adjusting the membership function of the FNN controller.

$$
C_{i}(k T)=C_{i}(k T-T)+p(k T)
$$

The estimated speed of an IPMSM using an ANN can be expressed as follows [16]:

$$
\begin{aligned}
\hat{\omega}_{r}(k+1)= & \hat{\omega}_{r}(k)+\Delta \hat{\omega}_{r}(k) \\
= & \hat{\omega}_{r}(k)-\frac{\Delta W_{2}(k)}{T} \\
= & \hat{\omega}_{r}(k)-\frac{\eta}{T}\left\{\frac{1}{c}\left[i_{q}(k)-\hat{i}_{q}(k)\right]\left[\hat{i}_{d}(k-1)+\frac{\phi_{a}}{L_{d}}\right]\right. \\
& \left.-c\left[i_{d}(k)-\hat{i}_{d}(k)\right] \hat{i}_{q}(k-1)\right\}-\frac{\alpha}{T} \Delta W_{2}(k-1)
\end{aligned}
$$




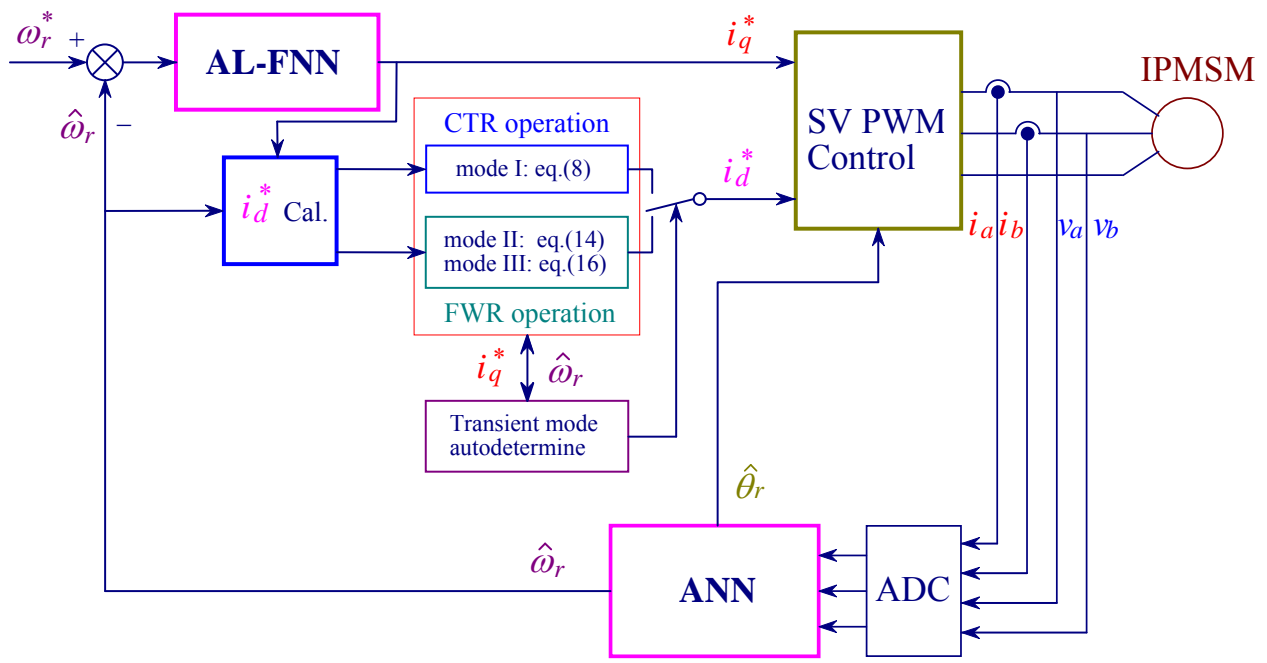

Fig. 9. Block diagram of maximum torque control with AL-FNN and ANN.

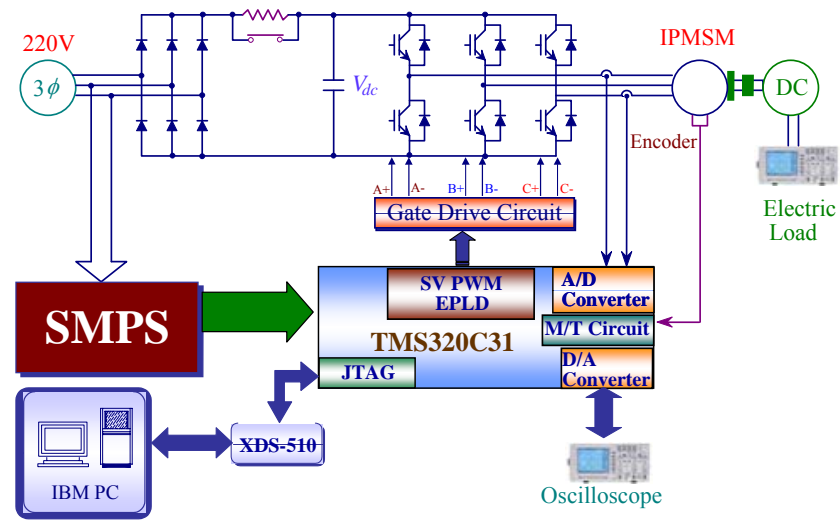

Fig. 10. The configuration of IPMSM drive system.

where, $T$ is the sampling period and $\eta$ is the learning coefficient. $\alpha$ is decided influence of the past weight that is changed by the existing weight.

The position of the rotor magnetic flux using the estimation speed is expressed as follows:

$$
\hat{\theta}_{r}(k+1)=\hat{\theta}_{r}(k)+T \cdot \hat{\omega}_{r}(k)
$$

Fig. 9 shows an overall block diagram of the maximum torque controller with an AL-FNN controller proposed in this paper. The operation mode for the maximum torque control is divided in three regions. Mode I is the CTR operation, while mode II and mode III are operated in FWR operation.

\section{EXPERIMENTAL RESULTS}

Fig. 10 shows the structure of the IPMSM drive designed to prove the validity of the maximum torque control proposed in this paper.

An IPMSM drive system is composed a digital control part and a power conversion part. The digital control part is composed of a pulse generation part to convert the PWM pulse from the inverter output voltage computed in a DSP, and an $\mathrm{A} / \mathrm{D}$ conversion part to convert to digital the analog value of the drive command voltage and current, part of the high speed computing process using a DSP. In addition, the power conversion part that operates the IPMSM through the on-off of the IGBT with a power semiconductor by a PWM pulse is composed. The IPMSM unites the DC motor, and the load device is composed of a DC motor connected to an electron load.

Fig. 11 and Fig. 12 show the response characteristic of the maximum torque control and the $I_{d}=0$ control when the load torque is increased $4[\mathrm{~N} \cdot \mathrm{m}]$ during the step command the speed is operated at $4000[\mathrm{rpm}]$ in the no load condition. Fig. (a) shows the command speed and the real speed, fig (b) shows the d-axis current, and fig (c) shows the generation torque. The maximum torque control reaches the steady-state more rapidly, has a smaller overshoot and a shorter rising time than the $I_{d}=0$ control.

Fig. 13 and Fig. 14 show the response characteristic of the maximum torque control and the $I_{d}=0$ control when the command speed is decreased to 3000 [rpm] from $4000[\mathrm{rpm}]$.

The maximum torque control proposed in this paper has excellent performance more than $I_{d}=0$ although command speed changing. 


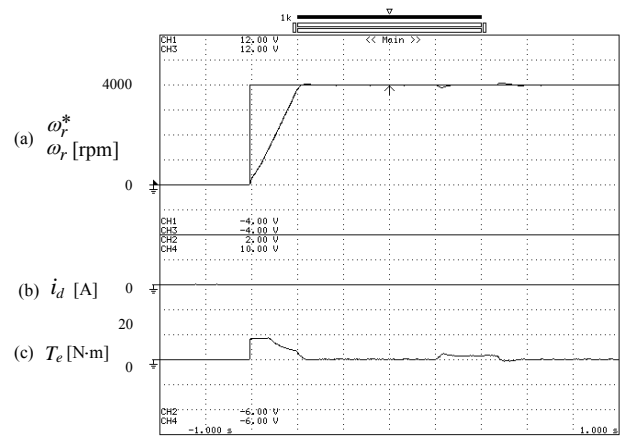

Fig. 11. Response characteristics of $I_{d}=0$ with command speed.

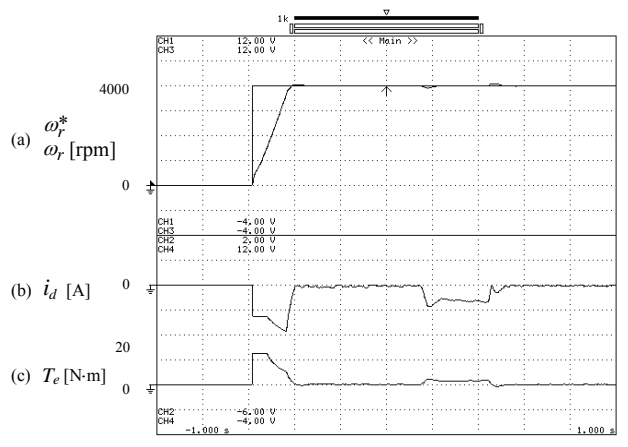

Fig. 12. Response characteristics of maximum torque control command speed.

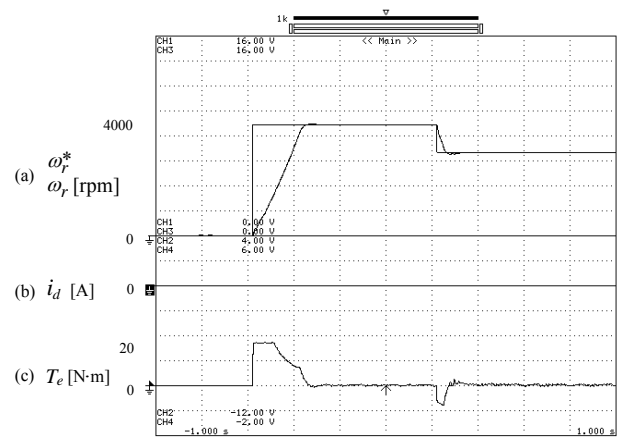

Fig. 13. Response characteristics of $I_{d}=0$ control in command speed change.

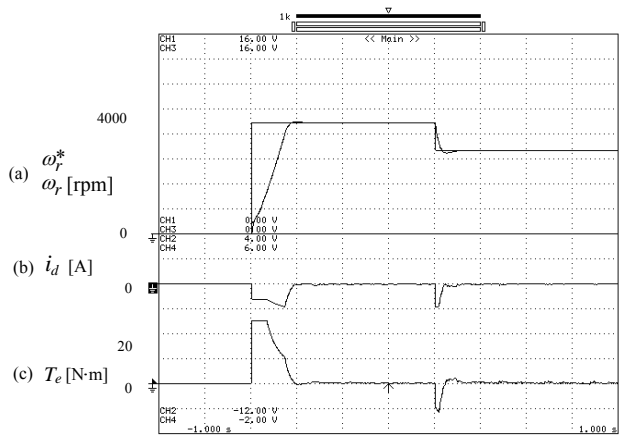

Fig. 14. Response characteristics of maximum torque control in command speed change.

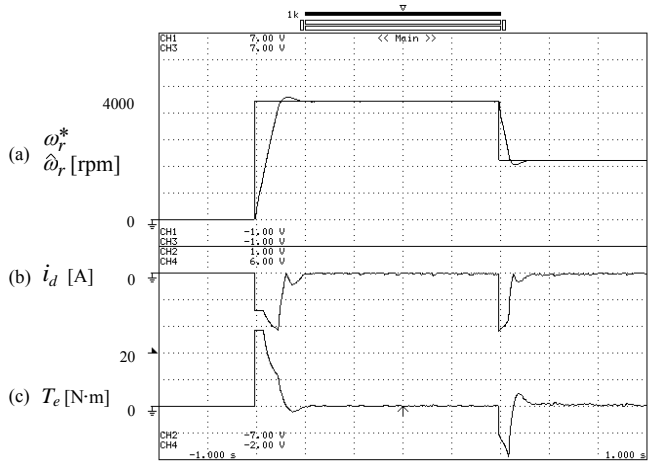

Fig. 15. Response characteristics of FNN in command speed change.

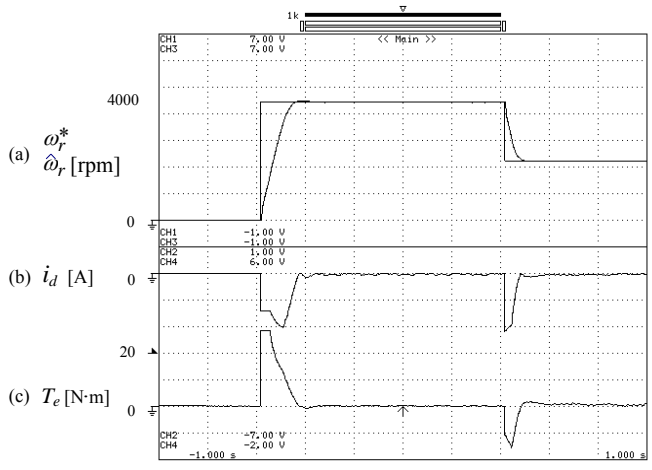

Fig. 16. Response characteristics of AL-FNN in command speed change.

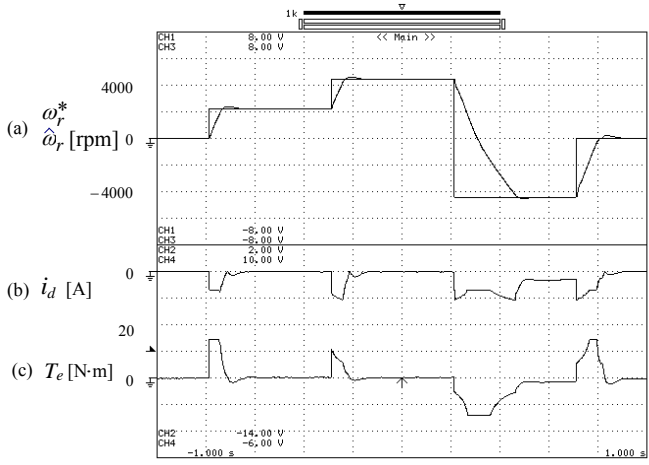

Fig. 17. Response characteristics of FNN in command speed change.

Fig. 15 and Fig. 16 show the response characteristics of the FNN and AL-FNN when the command speed is decreased to 2000 [rpm] from 4000[rpm] under the no load condition. Fig (a) shows the command speed, Fig (b) shows the d-axis current and Fig (c) shows the generation torque. The AL-FNN exhibits excellent performance such as a small overshoot, a fast rising time and fast arrival at the steady-state.

Fig. 17 and Fig 18 show the response characteristics of the various speed changes that that follow, $0[\mathrm{rpm}] \rightarrow 2000[\mathrm{rpm}]$ $\rightarrow 4000[\mathrm{rpm}] \rightarrow 0[\mathrm{rpm}]$ under the no load condition. Despite 


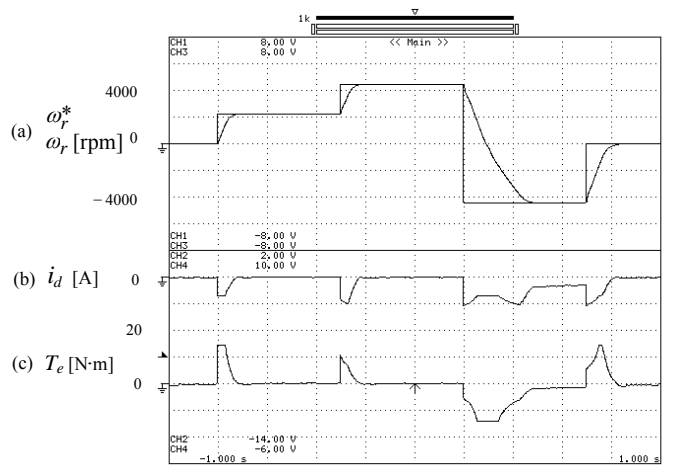

Fig. 18. Response characteristics of AL-FNN in command speed change.

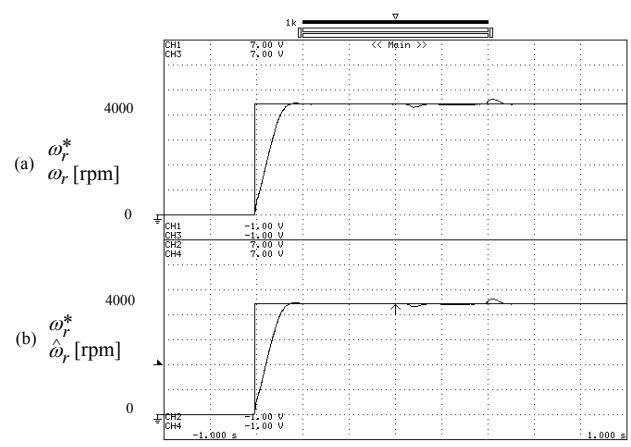

Fig. 19 Response characteristics of ANN with step command speed and load torque change.

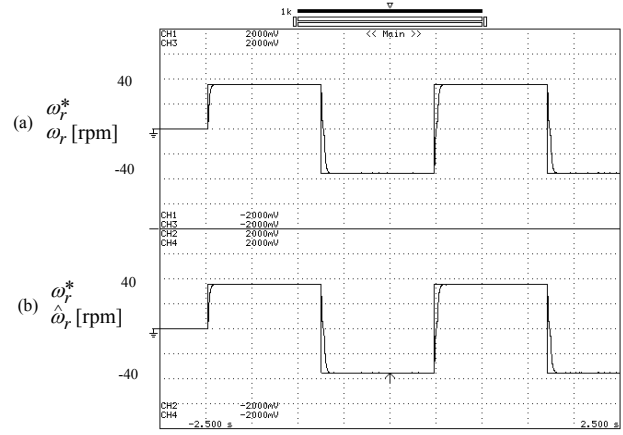

Fig. 20 Response characteristics of ANN with low speed command change and load torque.

the various speed changes, the AL-FNN controller is obtains better performance than FNN controller.

Fig. 19 shows the maximum torque control when the load is increased $4[\mathrm{~N} \cdot \mathrm{m}]$ during operation at $4000[\mathrm{rpm}]$ under the no load condition. The speed estimated using an ANN is similar to the real speed.

Fig. 20 shows the response characteristic of a low speed of $40[\mathrm{rpm}]$. In addition, the speed estimation in the low speed region shows excellent performance.

\section{CONCLUSIONS}

This paper proposes maximum torque control using an AL-FNN and an ANN for an IPMSM drive. The maximum torque control calculates the optimal d-axis current according to the operating conditions. Each control mode is controlled using this current. The maximum torque control proposed in this paper can obtain excellent response characteristics that are better than the conventional $I_{d}=0$ method in various conditions such as command speed and load torque changing. In addition, the AL-FNN controller shows excellent response characteristics that are better the than conventional FNN. The speed estimation using an ANN shows satisfactory results with an estimation error that is within $1 \%$.

This paper achieved the maximum torque control of an IPMSM using an AL-FNN controller, and it obtained satisfactory result in speed control and estimation. Therefore, the validity of the proposed controller is demonstrated by the performance results.

\section{APPENDIX}

Motor data:

$$
\begin{aligned}
& P=4, \quad R_{s}=0.57[\Omega], \quad \phi_{a}=0.108[\mathrm{~Wb}], \quad f=60[\mathrm{~Hz}], \\
& I_{a m}=15[\mathrm{~A}], \quad V_{a m}=120[\mathrm{~V}], \quad L_{d}=8.725[\mathrm{mH}], \\
& \left.L_{q}=22.8[\mathrm{mH}], \quad N=1800[\mathrm{rpm}], \text { and } T=4 \mathrm{~N} \cdot \mathrm{m}\right] .
\end{aligned}
$$

\section{REFERENCES}

[1] C. K. Lin, T. H. Liu, and C. H. Lo, "High performance sensorless IPMSM drive with a wide adjustable speed range," IECON 2008. 34th Annual Conference of IEEE, pp. 1222-1227, 2008.

[2] M. N. Uddin, "Comparative analysis of intelligent controllers for high performance interior permanent magnet synchronous motor drive systems," 2003 Large Engineering Systems Conference on Power Engineering, pp. 50-54, 2003.

[3] Mona N. Eskander, "Minimization of losses in permanent magnet synchronous motors using neural network," Journal of Power Electronic, Vol. 2, No. 3, pp 220-229, Jul. 2002.

[4] B. K. Bose and P. M. Szczesny, "A microcomputer-based control and simulation of an advanced IPM synchronous machines drive system for electric vehicle propulsion," IEEE Trans. Ind Electron., Vol. 35, No. 4, pp. 547-559, Nov. 1988.

[5] T. M. Jahns, "Flux weakening regime operation of an interior permanent magnet synchronous motor drive," IEEE Trans. Ind. Appl., Vol. 23, No. 4, pp. 681-689, Jul. 1987.

[6] S. R. Macmin and T. M. Jahns, "Control technique for interior high speed performance of interior PM synchronous motor drives," IEEE Trans. Ind. Appl., Vol. 27, No. 5, pp. 997-1004, Sep./Oct. 1991. 
[7] B. K. Bose, "A high performance inverter-fed drive system of an interior permanent magnet synchronous machines," IEEE Trans. Ind. Appl., Vol. 24, pp. 142-150, 1988.

[8] S. R. MacMinn and T. M. Jahns, "Control techniques for improved high performance of interior PM synchronous motor drives," IEEE Trans. Ind. Appl., Vol. 27, pp. 997-1004, Sep./Oct. 1991.

[9] S. Morimoto, M. Sanada, and Y. Taketa, "Wide speed operation of interior permanent magnet synchronous motors with high performance current regulator," IEEE Trans. Ind. Appl., Vol. 30, pp. 920-926, Jul./Aug. 1994.

[10] J. M. Kim and S.-K. Sul, "Speed control of interior permanent magnet synchronous motor drive for the flux weakening operation," IEEE Trans. Ind. Appl., vol. 33, No. 1, pp. 43-48, Jan./Feb. 1997.

[11] J. S. Ko, J. S. Choi, K. T. Park, B. S. Park, and D. H. Chung, "Development of HBPI controller for high performance control of IPMSM drive," ICPE'07, pp. 368-372, 2007.

[12] J. S. Choi, J. S. Ko, J. H. Lee, and D. H. Chung, "Speed control of IPMSM drive using neural network PI controller," CEE 06, pp. 102, 2006.

[13] J. S. Choi, J. S. Ko, J. H. Lee, and D. H. Chung, "Maximum torque control of IPMSM drive with ALC-FNN controller," ICEE 06, pp. 101, 2006.

[14] J. S. Ko, J. S. Choi, J. H. Lee, and D. H. Chung, "Maximum torque control of IPMSM drive with hybrid artificial intelligent controller," Proceeding of ICMATE'06, Session B1, pp. 177-182, 2006.

[15] H. G. Lee, S. M. Nam, J. S. Ko, J. S. Choi, J. C. Lee, and D. H. Chung, "The speed control and estimation of IPMSM using adaptive FNN and ANN," ICCAS 2005, p. 134, 2005.

[16] D. H. Chung, et al., "Speed sensorless control of IPMSM drive with ANN," KIEE Trans., Vol. 52P, No. 4, pp. 154-160, 2003.

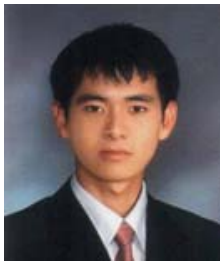

Jae-Sub Ko received his M.E. in Electrical Control Engineering from Sunchon National University, Sunchon, Korea, in 2005. He is currently working toward his Ph.D. in Electrical Control Engineering at Sunchon National University. His research interests include fuzzy control, neural networks, motor control and photovoltaic power generation. His current research focuses on maximum power point tracking control for PV generation.

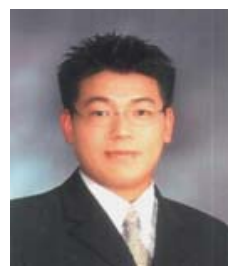

Jung-Sik Choi received his Ph.D. in Electrical Control Engineering from Sunchon National University, Sunchon, Korea, in 2010. He is a Senior Researcher at the Korea Electronics Technology Institute, Seongnam, Korea. His research interests include fuzzy control, neural networks, motor control and photovoltaic power generation. His current research focuses on maximum power point tracking control for PV generation.

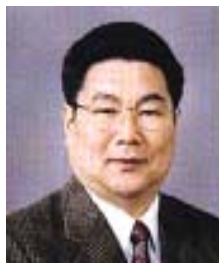

Dong-Hwa Chung received his Ph.D. in Electric Engineering from Hanyang University, Seoul, Korea, in 1987. He is a Professor of Electrical Control Engineering at Sunchon National University, Sunchon, Korea. His research interests include power electronics, electric motor control, AI control, fuzzy control, neural networks, motor control and photovoltaic power generation. His current research focuses on maximum power point tracking control for PV generation. He has received about twenty awards such as best paper and academic research awards, from the Korean Institute of Electrical Engineers and the Korean Institute of Illuminating and Electrical Installation Engineers, etc. He has authored about 100 papers since 1983. 